\title{
Aprender a Comprometerse
}

\author{
Juan Miguel Batalloso Navas ${ }^{1}$ \\ https://orcid.org/0000-0002-4982-4153
}

\section{Resumen}

El tiempo de las hermosas palabras y las grandes aspiraciones, si bien nos ha permitido iluminar nuestras conciencias y discernir lo que vale realmente la pena ser enseńado y aprendido, ya se ha terminado. Es ahora y no en un mańana prometeico, donde debemos aplicar, cada uno en el metro cuadrado que pisa, con nuestra conducta cotidiana comprometida, que realmente podemos construir espacios de convivencia más justos, solidarios y fraternos. Urge por tanto plantearse, no solo nuevas preguntas que nos conduzcan a nuevos saberes, sino sobre todo nuevas propuestas que se concreten en nuevos haceres y nuevas prácticas, pero no como ideales teóricos, sino como conducta y acciones visibles en lo cotidiano de nuestras aulas.

Palabras-clave: compromiso, sensibilidad, silencio, atención, afecto, amor, pensamiento crítico y responsabilidad social.

\section{Learn to Commit}

\section{Abstract}

The time for beautiful words and great aspirations, although it has allowed us to illuminate our consciences and discern what is really worth being taught and learned, is already over. It is now and not in a Promethean tomorrow, where we must apply, each one in the square meter that he steps on, with our committed daily conduct, that we can truly build fairer, more solidary and fraternal spaces of coexistence. Therefore, it is urgent to ask ourselves, not only new questions that lead us to new knowledge, but above all new proposals that materialize in new doings and new practices, but not as theoretical ideals, but as visible behavior and actions in the daily life of our classrooms.

Keywords: commitment, sensitivity, silence, attention, affection, love, critical thinking and social responsibility.

\section{Introducción}

Vivimos tiempos de una incertidumbre sobrecogedora. La pandemia del Covid-19 y la tragedia de más de 18 millones de contagios y 690.000

\footnotetext{
${ }^{1}$ Maestro de Primera Enseñanza. Orientador escolar y Doctor en Ciencias de la Educación por la Universidad de Sevilla (2005). batalloso@outlook.es.
} 
muertes en todo el mundo, nos ha instalado en una policrisis mundial de extraordinarias e incalculables dimensiones. Pero al mismo tiempo nos ha sumergido en un estado de inseguridad y temor cuyos efectos psicológicos individuales y colectivos, ponen de manifiesto que nuestro actual modo de vida es a todas luces insostenible. Si ya antes de la pandemia nuestras sociedades eran extraordinariamente desiguales en la distribución de la riqueza mundial y nacional, ahora la brecha entre ricos y pobres, no solo se ha ampliado, sino que se ha hecho más letal. Una vez más, el individualismo, el consumismo y la ausencia de vínculos sociales fuertes y sólidos, están ganando la batalla a la responsabilidad, la generosidad y la solidaridad. Y mientras tanto, el mundo económico, el político y el educativo sigue siendo incapaz de alumbrar cambios y transformaciones estratégicas capaces de ayudar a construir un mundo más justo, más fraterno, humano y sostenible.

Es verdad que en el mundo de las grandes instituciones y eventos académicos se siguen y siguen haciendo numerosas aportaciones que apuntan a la necesidad ineludible de un cambio de paradigma educativo. Pero es verdad también que todo ese grandísimo volumen de libros, artículos, conferencias y congresos no solo son ignorados por las políticas educativas nacionales e internacionales, sino que no acaban de aterrizar en las aulas en las que se forman y educan las grandes mayorías de la infancia y la juventud de nuestro planeta.

Baste recordar que en el Informe de la UNESCO de 1972 coordinado y dirigido por Edgar Faure, que se titulaba "Aprender a ser" se afirmaba que la educación necesariamente tiene que ser un proceso permanente para toda la vida. Un proceso en el que deberían integrarse aspectos multidisciplinares e interdisciplinares que abarcasen tanto el conocimiento y el desarrollo científico-tecnológico, como el desarrollo humano, entendido éste en su dimensión ético-política y en su dimensión personal. De aquel Informe ha pasado ya casi medio siglo, pero sus propuestas y orientaciones, no solo siguen vigentes, sino que son tal vez más necesarias que nunca dada la crisis en la que estamos inmersos. (FAURE, 1973 p. 127).

Veinticinco años más tarde, en 1996, la UNESCO, bajo la presidencia de D. Federico Mayor Zaragoza, publica el conocido Informe Delors titulado "La educación encierra un tesoro" en el que se da cuenta de los famosos cuatro pilares de la educación (aprender a conocer, aprender a hacer, aprender a vivir juntos y aprender a ser), pilares que son entendidos en un sentido global, armónico y sustentable del desarrollo humano. (DELORS, 1996 p. 90-108).

Por último y en 1999, la UNESCO, insistiendo en la extraordinaria y capital importancia que tiene el hecho de sentar unas mínimas bases para la 
educación del siglo XXI, promueve y edita la conocida obra de Edgar Morin de "Los siete saberes de la educación para el futuro" (MORIN, E.; 2011). En ella se proponen las conocidas siete grandes líneas transversales de fundamentación e intervención educativa: las cegueras del conocimiento; los principios del conocimiento pertinente; la condición humana; la identidad terrenal; enfrentar las incertidumbres; la comprensión y la ética del género humano, líneas que a nuestro juicio podrían quedar integradas en la cartografia del desarrollo humano propuesta por Ken Wilber (WILBER, K.; 2001, 2007).

Llegados a este punto, lo cierto es que estos saberes transversales del «aprender a ser» que a lo largo de los últimos cincuenta años se han ido proponiendo en los distintos informes de la UNESCO, así como también en los discursos justificativos de las diferentes reformas educativas que se han llevado a cabo a lo largo y ancho del mundo, apenas han impregnado las prácticas cotidianas de nuestras escuelas y centros educativos.

Pero si ya el "aprender a ser" es un eje transversal insustituible de cualquier proceso verdaderamente educativo, este eje sería insostenible, desarmónico, desequilibrado e incompleto, sino estuviese fuertemente asociado y a unido con el "aprender a estar". Si "aprender a ser" significa iniciar y continuar un proceso interminable de conocimiento de sí mismo y de desarrollo de valores éticos y espirituales en el sentido de buscar y encontrar paz interior aprendiendo a amar incondicionalmente, "aprender a estar" no es más que aprender a comprometerse con los valores éticos que fundamentan los Derechos Humanos Universales. Aprender, no solo a comprender y concebir mentalmente el significado y el sentido de la responsabilidad, la justicia, la solidaridad y el amor, sino sobre todo a comportarse en todo momento y en todo lugar conforme a esos principios de vida y esperanza.

El tiempo de las hermosas palabras y las grandes aspiraciones, si bien nos ha permitido iluminar nuestras conciencias y discernir lo que vale realmente la pena ser enseñado y aprendido, ya se ha terminado. Es ahora y no en un mañana prometeico, donde debemos aplicar, cada uno en el metro cuadrado que pisa, con nuestra conducta cotidiana comprometida, que realmente podemos construir espacios de convivencia más justos, solidarios y fraternos. Una conducta, por cierto, que únicamente podemos evaluar mediante hechos y no mediante intenciones, promesas y buenos deseos. Urge por tanto plantearse, no solo nuevas preguntas que nos conduzcan a nuevos saberes, sino sobre todo nuevas propuestas que se concreten en nuevos haceres y nuevas prácticas, pero no como ideales teóricos, sino como conducta y acciones visibles en lo cotidiano de nuestras aulas. 
Para empezar, habría que preguntarse ¿Qué es lo que realmente hace que un docente trabaje y se comporte de forma comprometida y natural con la Educación y se entregue plenamente a sus alumnos? ¿Qué es lo que hace posible que existan personas radical y absolutamente comprometidas con los valores de justicia, libertad, responsabilidad y solidaridad? ¿Acaso es solamente un atributo que únicamente los grandes héroes y santos pueden mostrar? ¿Qué cambios habría que operar en los sistemas educativos y en las organizaciones escolares para hacer posible que nuestros docentes y alumnos sean más responsables y solidarios? ¿Acaso podemos esperar de las Escuelas que produzcan transformaciones sociales, cuando las condiciones materiales de existencia de los docentes de Enseñanza Obligatoria son muchas veces infrahumanas e insostenibles? ¿No será que el mundo de la Academia, las Universidades y los Teóricos de la Educación está cada vez más alejado de la realidad educativa que viven diariamente los docentes de la Enseñanza Obligatoria? ¿No será que ese mundo se está convirtiendo, si es que no lo ha hecho ya, en un círculo selecto y endogámico de intelectuales de escaso impacto en la vida diaria de las Escuelas y cuyo discurso es cada vez más abstracto, teórico e impracticable?

Evidentemente, todas estas preguntas, si bien tengo la posibilidad de hacerlas, mi simple verdad es que no soy capaz de responderlas y si pudiese responderlas, necesariamente me tendría que remitir a la práctica real, o a las evaluaciones rigurosas y cualitativas de lo que ocurre realmente y día a día en nuestras aulas. Y es que el mundo de la Educación está tan profundamente burocratizado y determinado por las políticas económicas y sociales de los gobiernos de turno, que realmente los cambios visibles son muy escasos. Muy escasos, en lo que se refiere, no solo a las garantías, consolidación y extensión del Derecho Humano Universal a la Educación, sino también a los recursos y medios necesarios que los docentes y las Escuelas de Educación Obligatoria Pública necesitan para que ese Derecho sea plenamente efectivo.

Por todo esto, me atrevo a pensar, que, aunque debemos estar siempre alertas para reivindicar mejoras en las políticas educativas públicas, nada podríamos conseguir si los docentes no somos capaces de sumergirnos en un cambio profundo, no tanto de metodologías y técnicas, que también, sino en un cambio de conciencia personal y profesional. Cambio de conciencia, que nos permitiría afirmar y desarrollar tanto nuestra vocación y competencias profesionales, como nuestra propia persona en todas sus dimensiones. 


\section{Sensibilidad y conocimiento}

Nuestra experiencia de largos años dedicados a la Enseñanza Básica Obligatoria, nos dice que el primer paso en todo proceso educativo dirigido a que nuestros alumnos adquieran niveles más desarrollados de conciencia y por consiguiente ejecuten conductas cada vez más comprometidas consigo mismos, con los demás y con el entorno natural y social, es sin duda aprender a ser sensibles.

Aprender a ser sensibles es desde luego, aprender a reconocer e identificar sensaciones, es decir, reconocer e identificar los datos y la información procedente de nuestros órganos de los sentidos, al mismo tiempo que a tomar conciencia de que dichos datos provocan en nosotros emociones ya sean de agrado o desagrado, bienestar o malestar, placer o displacer. Esto significa también aprender a observar y a observarse, algo que jamás puede conseguirse si no ponemos en marcha procedimientos para incrementar, agudizar y enfocar nuestra atención.

No obstante, como muy acertada y sabiamente nos enseña Alexander Berzin la cuestión esencial radica en desarrollar una sensibilidad equilibrada :

...La sensibilidad tiene formas tanto físicas como mentales. La sensibilidad física del cuerpo depende del aparato sensorial o del sistema inmunológico. La sensibilidad mental es una cualidad de la mente y del corazón. Dicha sensibilidad puede ser al entorno, los negocios, la política, flora y fauna silvestre, otras personas o nosotros mismos. La sensibilidad es una función de dos variables: atención y respuesta. Cualquiera de ellas puede ser débil, fuera de proporción o equilibrada. Con atención, notamos la condición de alguien y las consecuencias de nuestro comportamiento hacia él o ella, o ambas. La respuesta nos permite una reacción espontánea o considerada a lo que notamos. Nosotros no reaccionamos solamente de una manera física o química ante lo que sucede a nuestro alrededor o dentro de nosotros mismos, respondemos con una emoción, un pensamiento, palabras, acciones o alguna combinación de estas cuatro. La sensibilidad equilibrada, es descubrir el balance entre ser sensibles ante lo que otros requieren, solicitan o exigen de nosotros y ser sensibles ante nuestras propias necesidades. Si constantemente proveemos a otros, sin poner límites, podemos abusar de nuestros recursos físicos y emocionales. Dicho síndrome, particularmente cuando va acompañado de una baja auto-estima o un complejo de mártir, no es sano para ninguno de los involucrados. De manera similar, si sólo consideramos nuestro punto 
de vista en las relaciones interpersonales, nuestra actitud narcisista nos va a apartar de los demás... (BERZIN. 1998 p.10).

En cuanto al conocimiento, debemos a Francisco Varela y a su Teoría de la Enacción, el descubrimiento de que las informaciones que obtenemos mediante nuestras sensaciones o el proceso de construcción de conocimiento no es una representación de un mundo exterior a nosotros que está ahí para ser incorporado por nuestra mente. Nuestros conocimientos no son espejos de un mundo o una mente independientes del sujeto cognoscente, sino que, por el contrario, hay que entenderlos como procesos activos de construcción, deconstrucción y reconstrucción de un mundo y una mente que son inseparables tanto del cuerpo y los mecanismos sensorio-motrices, como de la historia total de las acciones en las que el sujeto cognoscente participa en sus relaciones de interdependencia con el medio ambiente. La mente no es el reflejo de la realidad exterior o interior, como tampoco el conocimiento es una copia de un mundo o una mente pre-dados. La cognición es un proceso activo e interactivo corporizado en el que el individuo construye un mundo, que ni es una representación fiel de una realidad independiente que está ahí para ser copiada, captada o incorporada a la mente, como tampoco la realidad o el mundo son una proyección exclusivamente mental construida por el sujeto. (VARELA, F.: 1990: 240; 2000: 211).

Hasta aquí es muy fácil comprender que cada ser humano construye, deconstruye y reconstruye continuamente la realidad, en función de esa dinámica de acoplamiento estructural que cada sujeto como organismo vivo, de forma enteramente original desarrolla. Y es muy fácil comprender también, que el aprendizaje es siempre un proceso activo e interactivo, en consecuencia, todo lo que contribuya a la pasividad de los alumnos en el aula o fuera de ella, está en realidad negándoles su propia vida.

Pero ¿Qué es lo que hace que unos seres humanos sean más sensibles que otros, no solo en términos sensoriales, sino en términos de empatía, generosidad y compasión por los demás? ¿Qué es lo que hace que una persona se comprometa hasta tal punto con sus semejantes, siendo capaz de arriesgar su propia vida, seguridad y comodidad con tal de que el otro viva y/o mejore su situación vital y existencial? ¿No será que en la conducta comprometida intervienen otros procesos que actúan como fuerza motivadora y motriz capaz de que dicha conducta se convierta con el tiempo en una actitud permanente? 


\section{Emociones y afectividad}

A estas alturas del siglo XXI y con el extraordinario desarrollo alcanzado por las llamadas "Neurociencias", a nadie le deberían quedar ya dudas acerca del hecho de que el afecto y la emoción están siempre en el origen o en la base de cualquier proceso cognitivo y/o de aprendizaje. En consecuencia, el conocimiento y el desarrollo de las emociones, como la presencia de afectividad, son radicalmente esenciales e indispensables para aprender $y / o$ para poner en marcha cualquier proceso o acción educativa. Y esto dicho de manera más contundente, significa afirmar que educar es, antes que nada, facilitar experiencias emocionales y afectivas, de lo que se deduce la imposibilidad de pensar, idear, sentir y ejecutar compromisos, sin la presencia previa y continua de estas experiencias.

Efectivamente y tal como nos señala Francisco Mora, la trascendental importancia de las emociones para la enseñanza, el aprendizaje y la educación en general, se deriva de la constatación de que éstas cumplen un conjunto de funciones que son esenciales para la vida ya que sobre ellas descansan casi todas las funciones del cerebro. Así, por ejemplo, las emociones, además de aumentar la capacidad de memorizar acontecimientos, circunstancias, datos y dotar de significatividad al aprendizaje, son al mismo tiempo inseparables de los procesos de razonamiento y de los procesos decisionales. Juegan, por tanto, un papel fundamental en la generación de motivaciones, valores, intereses, actitudes y compromisos (MORA. 2000 p.: 27-28).

Pero además de las emociones y los sentimientos, otra dimensión transcendental de la cognición y de los procesos educativos, es la afectividad. En otras palabras: cognición, emociones, afectos y sentimientos forman parte de una unidad compleja que está en la base de todos nuestros pensamientos, acciones e interacciones con el medio social y natural.

Es evidente que cualquier fenómeno emocional es al mismo tiempo un fenómeno afectivo en cuanto que el mismo "afecta" o implica cambios corporales y mentales que dan lugar a un estado de ánimo o a un tono emocional más o menos duradero que puede transformarse en sentimientos. En este sentido Damásio señala que las emociones son procesos biológicos independientemente de que adquieran una determinada importancia, tonalidad o expresividad según las diferentes culturas y sociedades, es decir, el cuerpo es en realidad el "teatro de operaciones» de las emociones. En cambio, los sentimientos, son algo más elaborado mentalmente y no necesariamente utilizan el cuerpo como base de operaciones, aunque los sentimientos también 
utilizan el cuerpo para expresarse, ya sea de forma motriz, visual, simbólica, lingüística y estética (DAMASIO, A.; 2004). En cualquier caso, tanto emociones como sentimientos, "afectan" a los seres humanos y a los procesos cognitivos, siendo en realidad inseparables de los mismos. No obstante, aquí entendemos la afectividad de una forma más específica, aunque evidentemente en ella está implicada toda la vida mental, corporal, emocional y sentimental del individuo. La afectividad, desde esta especificidad, está referida al conjunto de aquellas emociones, sentimientos, acciones, respuestas, expresiones, conductas que podrían denominarse como de carácter amoroso, como la ternura, el acogimiento, la atención, el cuidado, la sensibilidad humana y social, la empatía, la comprensión, la compasión, etc.

Comprendiendo así la afectividad, coincidimos con Rolando Toro cuando afirma que

...la afectividad es la protección y nutrición de la especie humana formando vínculos y necesidades de amor indiscriminado por los seres humanos y por la vida en general, proporcionando seguridad a través de la ternura, solidaridad y compasión, es el permiso para dar y recibir...

$\mathrm{Y}$ en este sentido podemos diferenciar, como hace Toro, entre lo que se conoce como «inteligencia emocional» y la «inteligencia afectiva» (TORO, R. apud CAVALCANTE. 2004 p. 44-48), estando esta última centrada y expresada mediante sentimientos de amor, amistad, empatía, solidaridad y conciencia ética que inducen procesos adaptativos de aceptación incondicional, cuidado, compromiso y generosidad.

\section{Silencio, atención y pensamiento crítico}

Si la finalidad estratégica de todo proceso educativo dirigido a desarrollar la responsabilidad individual y social y por consiguiente el compromiso personal, social, moral, político y ecológico, necesariamente hay que comenzar por aprender a ser sensibles y afectuosos. Y el desarrollo de una sensibilidad equilibrada y de los afectos, no solo depende de la facilitación y de las oportunidades que cada individuo tiene de experimentar diferentes sensaciones y vivir diferentes acontecimientos, sino también de algo a lo que se ha prestado escasa importancia tanto a nivel teórico como a nivel práctico. Me estoy refiriendo a tres prácticas procedimentales indispensables si es que 
queremos realmente desarrollar la sensibilidad humana y social: el silencio, la atención y el pensamiento crítico.

Tal vez sea el silencio, como estado mental previo a toda experiencia sensorial de observación, lo primero que todo ser humano debería aprender para ser capaz después de reconocer, identificar y discernir, como de aprender a contemplar, mantener la calma y conseguir estados de sosiego, serenidad y paz interior. Obviamente en un mundo contaminado por un ensordecedor ruido de informaciones tóxicas, así como atravesado por la rapidez, la inmediatez, la eficacia, la competitividad o el pensamiento reactivo y productivo, destinar tiempos en el aula o en las familias a "hacer silencio" en nuestras mentes, utilizando cualquiera de los numerosos procedimientos de meditación y relajación de los que disponemos, es considerado como "perder el tiempo". Por desgracia nuestras Escuelas, más que espacios en los que podemos desarrollarnos como personas y aprender a conocer, reconocer y comprometernos con valores éticos y espirituales, son en realidad apéndices de un utilitario sistema mercantil, capitalista y patriarcal asociado a una gigantesca maquinaria burocrática en la que aprender a ser como decía aquel Informe de la Unesco de 1972, no pasa de ser una simple referencia bibliográfica.

En segundo lugar, o mejor al mismo tiempo, para aprender a ser sensibles y poder experimentar y reconocer emociones y afectos, necesariamente tenemos que aprender a prestar atención, o mejor que "prestar", lo cual induce a pensar que es algo ańadido y circunstancial, deberíamos en realidad "aprender a hacer atención". Se trata en suma de comportarnos de tal modo, que nos podamos sumergir en estados mentales de concentración y discernimiento, no solo en la tarea, no solo en la escucha activa de nuestros semejantes, sino también en las sensaciones internas que experimentamos al realizarla. Sin ser capaces de atención, es imposible que podamos desarrollar una sensibilidad equilibrada, como tampoco nuestra capacidad de observar y sentir más allá de lo que aparente o superficialmente nos indican nuestras sensaciones. A su vez, una persona "atenta" no es solamente aquella que es capaz de discernimiento y claridad perceptiva, sino también aquella que se inclina por realizar acciones y comportamientos de cuidado, sostenimiento y respeto profundo tanto a la vida humana como a la vida en todo el planeta. Sin atención, no es posible que seamos capaces de comprometernos con causas nobles y justas fundadas en valores éticos universales y de realizar acciones efectivas de cuidado, ayuda, generosidad, cooperación y solidaridad en nuestra vida cotidiana. 
Pero el silencio y la atención, aunque son realmente indispensables para aprender a ser sensibles, responsables y a comprometerse con uno mismo y con los demás, no son suficientes para que nuestras acciones sean realmente efectivas y coherentes con los fines que pretendemos. Necesitamos de otro componente, que por desgracia también es algo puramente marginal o inexistente en la vida diaria de nuestras Escuelas. Me estoy refiriendo al pensamiento interrogativo, crítico y autocrítico. $\mathrm{Y}$ es que nuestras Escuelas siguen montadas, estructuradas $y$ orientadas por un curriculum exclusivamente disciplinar y fragmentario cuya finalidad consiste en que nuestros alumnos memoricen respuestas para ser reproducidas conforme las normas y autoridades académicas determinen o exijan.

Fue Paulo Freire quien nos enseńó que todo proceso educativo liberador y de naturaleza democrática es también un proceso de toma de conciencia y de desarrollo del pensamiento crítico. Comprometerse con uno mismo, con los demás, con nuestro trabajo, con nuestro contexto, con la sociedad o con nuestro país, para buscar, encontrar y aplicar medidas efectivas y fundadas éticamente que mejoren una determinada situación o que restauren el actual desorden social establecido, es imposible si no desarrollamos nuestra conciencia crítica y autocrítica. Y claro está que, si nuestras Escuelas e instituciones formativas siguen y siguen funcionando a base de transmitir contenidos de escasa significación para el desarrollo personal y comunitario, aprender a ser responsables socialmente y a comprometerse con uno mismo y con nuestros semejantes, es y será siempre un objetivo inalcanzable.

Desgraciadamente, el concepto de Freire de educación bancaria sigue vigente, sobre todo cuando además sabemos que la saturación de información a la que estamos sometidos nos está impidiendo analizar, sintetizar y procesar aquellas informaciones relevantes y significativas para nuestro desarrollo humano. Pero también cuando constatamos que la acumulación de datos o informaciones no produce conocimientos, ni tampoco la acumulación de conocimientos genera una sabiduría capaz de hacer frente a los problemas de la vida diaria o de nuestro entorno cercano y lejano. Y es que la acumulación de datos, la mayoría de las veces deriva en desinformación, manipulación, intoxicación informativa y en último término en búsqueda de conformidad o domesticación.

Así pues, aprender a comprometerse, además de todo lo anterior, exige necesariamente el ejercicio del pensamiento crítico y autocrítico, que es aquel que nos permite identificar, analizar, valorar y enjuiciar con criterios racionales y éticos cualquier situación humana, social o vital. Y esto no es algo 
que se aprende de un día para otro, sino que por el contrario emerge a partir de una actitud inquisitiva e interrogativa permanente, siendo capaz como decía Paulo Freire de preguntarse siempre por quien se beneficia o quien se perjudica de una determinada situación o hecho y por qué sucede así. (FREIRE, P.; 1975; 1976; 1999)

\section{Actividad coherente}

Reconocer, identificar, apostar y comprometerse con todo aquello que permite concretar y expresar la igualdad de dignidad de todos los seres humanos sin excepción, o simplemente comportarnos fraternalmente con nuestros semejantes, no es algo que pueda conseguirse exclusivamente con silencio, atención, abrazos y esa forma de compasión negativa que solo se queda en un sentimiento fugaz de lástima y conmiseración. Aprender a comprometerse, necesariamente exige acción, actividad, hechos observables y conducta visible, sin embargo, nuestros sistemas educativos siguen anclados en la pasividad, aunque ahora se disfrace con actividad mental y uso y abuso de las nuevas tecnologías.

Mantener a una persona en la pasividad, hacer que una persona permanezca sin desplegar su natural tendencia psicobiológica a la actividad, e incluso más, ignorar la historia total de esa persona y de sus características corporales, biográficas y sociales, es reducirla al estado de mera cosa. Esta es la razón por la que el principio pedagógico de actividad no consiste en hacer que los alumnos estén permanentemente ocupados, no radica en satisfacer las naturales tendencias internas al movimiento o las lógicas reacciones a los estímulos y condiciones del ambiente. No se trata tanto de que el alumno reaccione a los estímulos que se le ofrecen, sino más bien de que el alumno desde su propio sentido común, desde su propia historia total ponga en marcha sus recursos y capacidades. Lo esencial no reside en el ejercicio de una enseńanza reactiva y por consiguiente condicionada, sino en el desarrollo de una enseñanza activa que funcionE dirigida por motivaciones intrínsecas.

El hecho evidente de que todos los sistemas de enseńanza del mundo hayan primado siempre lo mental sobre lo corporal, lo intelectual sobre lo manual, la razón sobre la emoción, lo conceptual sobre lo estético y lo individual sobre lo social, se debe precisamente a la naturalizada asunción de una concepción del conocimiento basada en que «...1) el mundo es predefinido: 2) nuestra cognición aprehende este mundo, aunque sea en forma parcial: y 3) el 
modo en que conocemos este mundo predefinido consiste en representar sus rasgos y luego actuar sobre la base de estas representaciones...» (VARELA. 1990 p. 99)

Así pues, para aprender a comprometerse, no solo hay aprender a hacer y aprender a aprender como dicen los Informes de la Unesco, sino sobre todo aprender a realizar acciones o comportamientos coherentes. Y como sabemos, toda actividad o comportamiento coherente es aquel en el que la distancia entre lo pretendido, deseado o formulado como intenciones y lo realizado, lo hecho y lo expresado como conducta es siempre mínima. Dicho de otra manera: toda acción coherente es aquella que expresa una correspondencia biunívoca entre el sentir, el pensar, el decir y el hacer.

Bajo este principio entonces, la actividad no consiste en responder mecánicamente a los estímulos que el contexto o el profesor se encarga de proporcionar, sino que es más bien una experiencia por la que el alumno se encuentra a sí mismo con los demás, y por la que se afirma y se descubre como sujeto capaz de aprender y desarrollarse por sí mismo en el convencimiento de que posee un valor original intransferible. En consecuencia, la actividad del alumno, más que una acción de obligado cumplimiento, más que un deber de obediencia ante la persecución de un título o una credencial académica, o de una finalidad extrínseca al proceso, se convierte por el contrario en una finalidad intrínseca. Aprender a actuar o a comportarse de un modo coherente, no es más que un aspecto del aprendizaje de la responsabilidad y de la libertad. Y aquí el elemento principal reside en que cada alumno o cada docente perciba desde su fuero interno y sin necesidad de apoyos o estímulos externos, que su ser, su persona es algo esencialmente valioso y único. Obviamente, esa percepción de la propia valía (autoestima) tiene una extraordinaria importancia a efectos metodológicos, puesto que, a partir de esta consideración, la actividad de los alumnos ya no podrá servir para comparar, competir, emular, copiar, seleccionar o depender del profesor o de fuentes externas para afirmarse como persona y comportarse coherentemente.

Aprender a comprometerse es un proceso imposible, si un ser humano, o en nuestro caso, el alumnado, no tiene posibilidades de actuar en libertad. No se trata de que el alumno haga cosas para que tenga, obtenga o consiga determinados fines, sino más bien de que las haga para que sea y llegue a ser más él mismo como ser original y único, al mismo tiempo que disfruta y es feliz haciéndolas. No es el tener lo que mueve aquí el principio de actividad sino el ser. Más que poner a los alumnos en condiciones para que actúen o para que se muevan; más que construir un escenario para dramatizar un juego en el que los alumnos sean meros actores dirigidos; más que mantenerlos entretenidos en actividades orientadas al "tener", de lo que se trata es de 
garantizar un clima y unas posibilidades para que el objetivo de actuar pueda también desarrollarse en todas las dimensiones de su existencia como ser. Se trata pues de que nuestros alumnos puedan libremente reflexionar, criticar, mejorar, compartir, expresar, escuchar, comprender, comunicar, sentirse útiles a los demás y a la comunidad a la que pertenecen. Y esto evidentemente requiere reconocerse a sí mismo y ante los demás como un ser originalmente valioso, no por lo que se tiene, se posea o se consiga, sino por lo que realmente es: un ser singular e intransferible que no puede ser tratado ni como un objeto, ni como un recipiente a ser llenado, y por tanto con capacidad de crítica y autocrítica. En esta medida la actividad coherente se convierte al mismo tiempo en principio de reflexión, expresión, comunicación y acción, o si se prefiere, de liberación.

Fue Erich Fromm el que nos enseñó que el concepto actual que tenemos del significado del término "actividad" no diferencia entre lo que es "estar activo" y "estar ocupado" ya que

...en la actividad alienada no siento ser el sujeto activo de mi actividad; en cambio, noto el producto de mi actividad, algo que está "allî", algo distinto de mí, que está encima de mí y que se opone a mí. En la actividad alienada realmente no actúo: soy activado por fuerzas internas o externas. Me vuelvo ajeno al resultado de mi actividad... (FROMM. 1992 p. 94).

Es de suma transcendencia, por tanto, diferenciar la actividad que nos aleja de la naturaleza de nuestro propio ser de aquella otra que nos humaniza, nos desarrolla y nos permite aprender y comprometernos. Nunca puede ser igual, la actividad que nos enajena y esclaviza, que nos suprime o nos limita como seres humanos, que nos hace sucumbir ante fuerzas que nos dominan y escapan a nuestro control y nos convierten en mera cosa, que aquella otra actividad que nos libera, que nos ensancha en cuanto que nos permite desplegar nuestro propio ser, nuestra propia vocación haciéndonos realmente sujetos protagonistas de nuestro propio proceso de desarrollo personal y de nuestro propio destino. Sin actividad autónoma, que exige necesariamente climas psicosociales de libertad y motivaciones intrínseca, no es posible que nos comprometamos con nosotros mismos y con los demás o que dancemos constructivamente con la realidad a la que pertenecemos y estamos acoplados. 


\section{Complejidad, compromiso y voluntad}

Toda acción y en particular las acciones educativas, en las que se ponen en juego emociones, sentimientos, conductas, valores, aprendizajes, ideas y condiciones previas, etc. poseen un carácter recursivo en el sentido de que son autorreferentes, se apoyan en ideas previas, preconcepciones pero también son autopoiéticas (MATURANA, H. y VARELA, F.; 1996), se están produciendo y reproduciendo continuamente a sí mismas, porque los seres humanos somos productores y producto de nuestras propias producciones. Son pues los procesos autopoiéticos que se generan en los ambientes de aprendizaje como consecuencia de los procesos recursivos, los que dan ese carácter de permanencia, cambio, dinamicidad, continuidad a cualquier proceso educativo. De aquí se deduce que cualquier práctica pedagógica tiene que ser necesariamente flexible, abierta a los cambios, a la incertidumbre, a la inseguridad, a las interferencias, cruces, bifurcaciones, sorpresas y paradojas (MORAES, Maria C.; 2008: 101), es decir, exige compromiso. Pero, además, toda acción, una vez realizada escapa al control del sujeto que la inició y cualquier cosa imprevisible puede efectivamente suceder, porque esa acción al pertenecer a un contexto de interacciones es el contexto, cercano y lejano el que de alguna manera influencia y conduce los posibles efectos de la misma de tal forma que incluso dichos efectos pueden volver contrarios a la intención inicial u original. ("principio de ecología de la acción») (MORIN, E.; 1994)

De lo anterior se desprende que las actitudes de cuidado, atención, observación, escucha, empatía, aceptación incondicional, ayuda, apoyo, responsabilidad, conciencia, tolerancia, mediación, diálogo, no son ya exclusivamente intenciones o valores éticos, o recomendaciones metodológicas generales de buena voluntad, sino elementos ontológicos, esencialmente constitutivos de los procesos educativos dada su naturaleza recursiva, compleja e imprevisible. Elementos que necesariamente exigen de los profesores acciones efectivas comprometidas. Y si los profesores son personas y profesionales comprometidos, sus alumnos también llegarán a serlo.

Por último, comprender la complejidad de los fenómenos y procesos educativos y asumir que es imposible facilitarlos o desarrollarlos si no es a partir del compromiso que exigen todas las relaciones afectivas, cariñosas, respetuosas y en definitiva amorosas, necesita de la intervención de un elemento nuevo: la voluntad. Sin la voluntad de buscar el modo de experimentar satisfacción por lo que hacemos y de autorrealizarnos en la tarea. 
Sin la voluntad de hacer las cosas lo mejor que podemos y sabemos. Sin la voluntad de autoconocernos y de identificar nuestros errores y contradicciones para mejorarnos y mejorar nuestras acciones. Sin la voluntad por aprender permanentemente y regalar a nuestros alumnos la mejor persona y el mejor profesor que podemos llegar a ser. Sin la voluntad de estar apasionado por el conocimiento, la enseńanza y educación. $\mathrm{O}$ sin la voluntad de amar realmente a nuetros alumnos y el ejercicio de nuestras competencias y habilidades, es imposible que consigamos docentes y alumnos comprometidos.

En este sentido, consideramos importante recordar que el término «voluntad» generalmente ha estado asociado a conceptos que se asimilan a esfuerzo, disciplina, sacrificio, riesgo, obediencia, represión, autoritarismo y en general a la idea de deber como imperativo destinado a ser hecho y cumplido sin deliberación y por simple mandato categórico. Y esto ha sido así porque a «la voluntad» se la ha considerado como una facultad y no como la misma inteligencia en acción en la que está implicada la persona entera como unidad indivisible: «...lo que llamamos voluntad es en gran parte un proyecto de la inteligencia humana para conseguir autodeterminarse, realizado mediante una la creación social y convertido en estructura psicológica durante el proceso educativo..." (MARINA. 1997 p. 180), por tanto, la voluntad no nace de la obediencia, ni de la represión sino del desarrollo de nuestra inteligencia que es al mismo tiempo social, corporal, racional, emocional y espiritual.

Desarrollar la voluntad es exactamente lo mismo que idear, elaborar, analizar, reflexionar, ejecutar y evaluar decisiones, sabiendo que la inteligencia como dice Marina consiste también en la capacidad de darse a uno mismo órdenes diferenciando entre valores pensados, valores sentidos y valores vividos: "...la voluntad se aprende mediante la obediencia a una idea, a un proyecto, a una vocación...». Y en este caso, la obediencia no es negación de autonomía sino afirmación de la propia libertad que se ejerce inserta en un medio y que por tanto está sujeta a interdependencia y no al arbitrio de la satisfacción de todo tipo de deseos. La voluntad es por tanto «...la dirección inteligente de la conducta...» (MARIN. 1997 p. 185).

\section{Conclusión provisional}

Con estas breves reflexiones he intentado mostrar que aprender a comprometerse, aprender a asumir responsabilidades individuales y colectivas, o aprender a entregarse apasionadamente a una tarea, un proyecto, una causa, una persona es la única dimensión educativa que nos puede salvar de la actual 
incoherencia y deshumanización por la que atraviesan todos los sistemas educativos del mundo. Y aquí hay que incluir, no solo los sistemas educativos y formativos reglados o formales, sino también a los informales, ya sean la familia, los grupos, las organizaciones o las instituciones.

Corresponde pues a los educadores, formadores y docentes, así como a todas las estructuras e instituciones educativas, crear las condiciones psicosociales y afectivas necesarias para que el aprendizaje y la formación estén atravesadas y fundadas en sentimientos y emociones amorosas capaces de construir lazos y vínculos de colaboración, cooperarción, responsabilidad y solidaridad. Como dice Francisco Mora: «solo se puede aprender aquello que se ama» (MORA, F.; 2013) lo que se corresponde también con la evidencia de que solo se puede enseñar aquello que también se ama, como nos decía Paulo Freire. (FREIRE, P.; 1997).

En consecuencia, no podemos en ningún caso perder la esperanza, sencillamente porque la esperanza, no solo es un constitutivo ontológico de cualquier ser humano (FREIRE, P.; 1993), sino también de cualquier proceso educativo que en realidad es una apuesta radical por un proceso permanente e inacabado de humanización. Y sin esperanza que idea, proyecta, actúa y se mueve en la dirección de la vida y el amor, no puede haber compromisos capaces de construir, desde nuestro metro cuadrado, un mundo más justo, más fraterno, más responsable, más humano y cuidadoso, sostenible y respetuoso con la Naturaleza. Y esto es algo que la doctora Maria Cândida Moraes entiende muy bien cuando afirma que el amor y la solidaridad implica

...a integração entre o sentir, o pensar e o agir, a integração entre razão e emoção, o resgate dos sentimentos como expressão de nossa verdade interior. É educar visando a restauraçáo da inteireza humana e conspirar a favor da multidimensionalidade do ser. Educar na biologia do amor é cuidar do desenvolvimento do pensamento e das inteligências e, ao mesmo tempo, educar para a escuta do sentimento e abertura do coração. Para tanto, é necessário criar um espaço acolhedor, desafiante, amoroso e não competitivo, um espaço onde se corrija o fazer em contínuo diálogo com o ser... (MORAES. 2003 p. $5)$.

\section{Referências}

BERZIN, Alexander. Desarrollo De Una Sensibilidad Equilibrada. Ejercicios Prácticos de Budismo para la Vida Cotidiana. 1998. Disponível em 
$<$ https://budismolibre.mx/docs/libros_budistas/Berzin_Alexander_Desarroll o_De_Una_Sensibilidad_Equilibrada.PDF > Aceso em: 5 ago. 2020.

DAMASIO, Antonio R. El error de Descartes. Barcelona: Crítica. 2004.

DELORS, Jacques. La educación encierra un tesoro. Informe a la UNESCO de la Comisión Internacional sobre la educación para el siglo XXI. Madrid. Santillana-Unesco. 1996.

FAURE, Edgar. Et al. Aprender a ser. Madrid. Alianza-Unesco. 1973.

FREIRE, Paulo. Pedagogía del oprimido. Madrid: Siglo XXI. 1975.

. La educación como práctica de la libertad. Madrid. Siglo XXI. 1976.

- Pedagogía de la esperanza. Un reencuentro con la pedagogía del oprimido. Madrid: Siglo XXI. 1993.

- Pedagogía de la autonomía. Saberes necesarios para la práctica educativa. 3a Ed. Madrid: Siglo XXI. 1999.

FROMM, Erich. ¿Tener o ser? Barcelona. Paidós. 1992.

MATURANA, Humbeto. y VARELA, Francisco. El árbol del conocimiento. Barcelona. Debate. 1996.

MARINA, José. A. El misterio de la voluntad perdida. Barcelona. Anagrama. 1997.

MORA, Francisco. El cerebro sintiente. Barcelona: Ariel. 2000.

MORAES, Maria C. Educar na biologia do amor e da solidariedade. Petrópolis. Vozes. 2003.

- Ecologia dos saberes. Complexidade, transdisciplinariedade e educaçáo. Novos fundamentos para iluminar novas práticas educacionais. Sáo Paulo. Willis Harman House/Antakarana. 2008.

MORÍN, Edgar. Introducción al pensamiento complejo. Gedisa. Barcelona. 1994.

Os sete saberes necessários à educação do futuro. Cortez\&UNESCO. Brasília. 2011.

VARELA, Francisco. Conocer. Las ciencias cognitivas, tendencias y perspectivas : cartografía de las ideas actuales. Barcelona. Gedisa. 1990. . El fenómeno de la vida. Santiago de Chile: Dolmen. 2000. 
32 Polyphonía, v. 32/1, jan.-jun. 2021

WILBER, Ken. Una teoría del todo. Barcelona. Kairós. 2001. . Espiritualidad integral. Barcelona. Kairós. 2007. Recebido em: 05 ago. 2020 Aceito em: 09 dez. 2020 